\title{
Research on Inventory Control of Cement Equipment Manufacturing Enterprise in Supply Chain Environment
}

\author{
Luo Xu \\ Wuhan University of Technology, Wuhan 430070, China
}

\begin{abstract}
For manufacturing enterprises, holding a certain amount of inventory is necessary, excess inventory is not only useless but also occupied capital, therefore, inventory control is a good way to optimize the inventory structure as well as to improve the utilization of the funds manufacturing enterprise. In this paper, the quantitative inventory control model is studied, and the economic order model and its calculation method are verified by the inventory control demand of the cement equipment manufacturing enterprise.

KEYWORD: Cement equipment manufacturing enterprise (CEME); Inventory management; Inventory control model; Economic order quantity (EOQ)
\end{abstract}

\section{INTRODUCTION}

Since the 90s of the 20th century, China has become a manufacturing powerhouse, manufacturing industry is in a period of rapid development, inventory investment in the total assets of the enterprise in the possession of the proportion has reached 30\%, whose management and utilization is directly related to the enterprise funds occupancy level and the operational efficiency of assets (Enright $\mathrm{M} \mathrm{J}$ et al, 2005). Under the different levels of inventory management, the average enterprise funds occupancy levels vary greatly, and the implementation of the correct method of inventory management, such as reducing the average enterprise funds occupancy levels and improving inventory turnover rate and total asset turnover rate, will ultimately improve the economic efficiency of enterprises. In addition, from the marketing point of view, as an important component of enterprise logistics, the cost reduction potential of inventory is far more than any other part of marketing, such as business logistics costs accounted for $50 \%$ of the cost of marketing, of which the inventory cost is about 35\%, and the logistics cost will account for $30 \%$ to $50 \%$ of the full costs of the product (Klausner $\mathrm{M}$ et al, 2000). All of the production process is only $5 \%$ of the time for processing and manufacturing, the remaining $95 \%$ of the time for storage and transportation. Thus, reducing the inventory cost has become "the third profit source" (Yi W, 2006).

\section{INVENTORY MANAGEMENT MODEL}

\subsection{Problem description}

Considering the characteristics of the customer order-driven, cement equipment manufacturing enterprise (CEME) still have some problems, mainly reflected in the following aspects:

\subsubsection{Inventory of raw materials}

In order to reduce production costs for certain raw materials, CEMEs try to set a certain safety stock to reduce procurement costs of raw materials, such as steel, standard parts and so on. But because of the type utility of material and the demand uncertainty makes a large backlog of inventory, increasing the inventory cost. At the same time, in order to ensure the supply of raw materials, suppliers will hold a lot of inventory cost, which leads to the inventory cost in the whole supply chain to further increase.

\subsubsection{Irrational material inventory settings}

During the manufacturing process, CEMEs relates to a variety kind of materials. In order to ensure the stability and continuity of production, enterprise set a certain degree of safety stock of materials to achieve the material supply, but the lack of reasonable and effective inventory warning strategy leading to a shortage of material and increasing risk of delayed delivery of orders. In this way, enterprises will not only decrease its reputation, but also cause great economic losses to the enterprise. 


\subsubsection{Low efficiency of information transfer system}

The supply and demand situation, inventory status and production situation of each enterprise are the important basis of supply chain management, and those information is mastered by different enterprise departments. Therefore, it is needed to establish the information sharing platform and realize the integration of all information. But the current situation is that a lot of companies can't realize the informatization. Once the flow of information is not smooth or appears error, production plan will be affected and products will be wrong or outdated, resulting in high inventory.

To solve these problems, an effective way is to establish a suitable inventory control strategy and model to improve the level of the inventory management of the CEMEs. Through optimizing inventory management, the coordination and management of supply chain members are strengthened so as to meet the needs of customers, improve the profit of enterprises, and enhance the competitiveness of enterprises.

\subsection{The control model of quantitative inventory}

The basic idea of the quantitative inventory control model can be described by Figure 1, in which $\mathrm{R}$ is the order point, $\mathrm{Q}$ is the order quantity, and $\mathrm{L}$ is the order lead time. The graph shows that when the stock is reduced to the order point $\mathrm{R}$, it should be carried out in batches to order Q and ensure to receive at the end of the L, so as to ensure the supply of inventory.

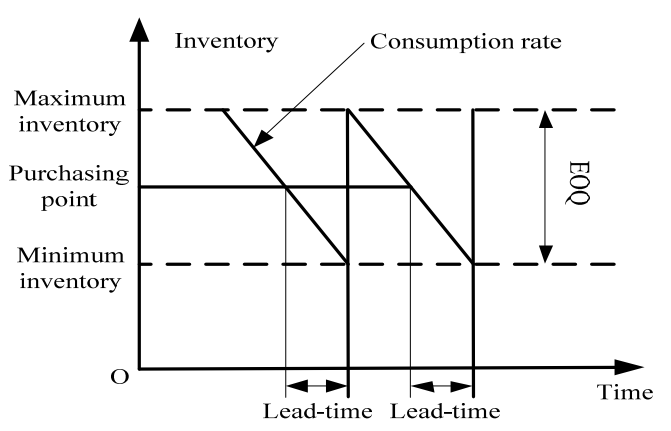

Fig 1 Quantitative inventory control model

Order quantity $\mathrm{Q}$ can be determined through the model of economic order quantity (EOQ), its basic principle is to require the total annual cost (annual inventory cost + annual product cost + annual procurement costs) minimum. Since the inventory costs increase with the increasing amount of inventory and the procurement costs reduce with the increasing procurement volume instead. As a result, when purchasing volume increases (procurement costs decrease), the stock will increase (inventory costs will increase). As the relationship shown in Figure 2.
Thus, it is a paradox between inventory cost and purchasing cost. In order to solve the problem, we need to find a reasonable order quantity to minimize the total cost. As shown in Figure 2 can be obtained by the following relationship: the total annual cost of inventory items $(\mathrm{TC})=$ goods cost + cost + annual procurement of inventory costs, that is:

$T C=D C+D S / Q+Q H / 2$

The D: annual demand of certain inventory items (year), D is a constant; C: procurement unit cost (yuan per piece), does not consider the discount, $\mathrm{C}$ is a constant; S: unit cost of ordering (yuan per times). Q: each order quantity (pieces); H: unit inventory storage cost per year on average (yuan per piece);

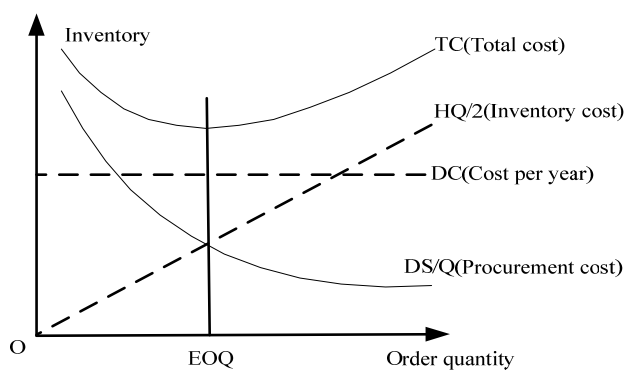

Fig 2 Economic order quantity schematics

If the TC meets the minimum, by taking the derivative of $Q$ derivative and making it equal to zero for the formula (1), the formula of EOQ can be described as:

$E O Q=\sqrt{2 D S / H}$

\section{LOGISTICS ANALYSIS AND SUPPLY CHAIN STRUCTURE OF CEME}

Supply chain, a whole function net chain structure of suppliers, manufacturers, distributors, retailers and end-users, is based on the core enterprise producing intermediate products and final products by controlling information flow, logistics, capital flow from the beginning of procuring of raw materials and finally sent products to consumers through the sales network.

The supply chain of cement industry equipment is a net chain structure, which is based on the CEMEs as the core, taking the parts suppliers of motor, gearbox, hydraulic pump and other parts and steel, standard parts, paint and other raw materials ad upstream, and end customers as downstream. Establish the supply chain structure model of the cement equipment industry which is as the core of CEMEs using modeling method of supply chain based on SCOR (Supply-chain operations reference model) (Stewart G, 1997), as shown in Figure 3 below. 


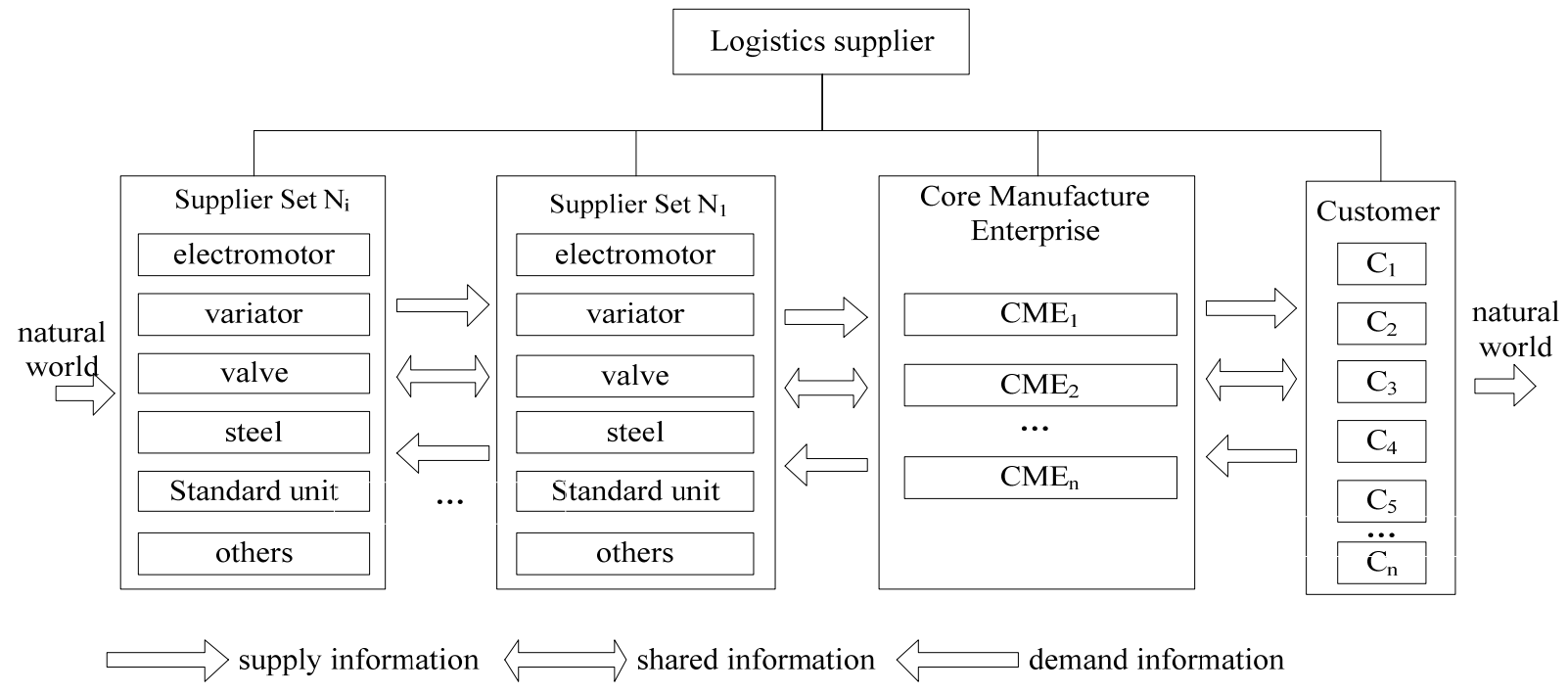

Fig 3 Supply chain structure of cement equipment industry

\section{SUPPLY CHAIN INVENTORY MODEL OF CEME}

\subsection{Model construction}

The supply chain structure of the CEME is simplified as the inventory model which takes the equipment manufacturing enterprise as the core, as shown in Figure 4. As the CEME is a customer order oriented manufacturing enterprise, the model consist of suppliers, core manufacturing enterprises and customers.

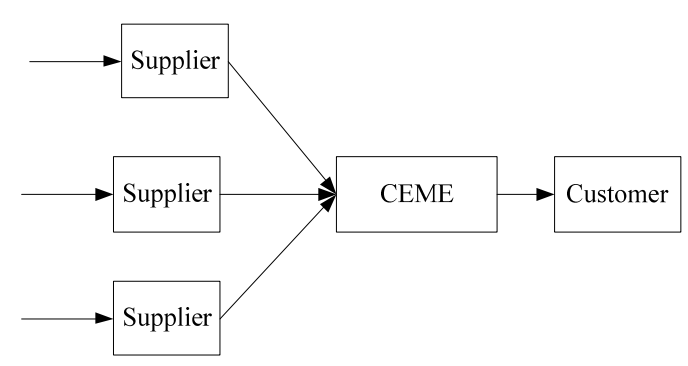

Fig 4 Supply chain inventory model of CEME

Through the supply chain network, the cooperation between suppliers and the core manufacturing enterprise, continuously reduce inventory costs, achieve supply chain information sharing, make sure don't happen out of stock, in the construction of the model, focus on the maintain of order costs and inventory costs.

\subsubsection{Ordering cost}

Ordering cost includes two contents: the product of the unit product price and order quantity is proportional to the relationship; ordering the cost has nothing to do with the quantity of goods.

\subsubsection{Inventory to maintain cost}

Inventory to maintain cost is mainly produced by the following items, the product of the scrap, damage and insurance costs, transportation and storage costs, to maintain cost of combining the transportation costs.

\subsubsection{The core manufacturing business inventories} CEMEs based on customer order driven productionoriented enterprises, assume that the demand for $M$, Ordering cost is $a_{1}$, remain the same, Unit price of the product is $c_{1}$ The inventory ratio is $r_{1}$, Order quantity is $Q_{1}$, Ordering cost for:

$C\left(Q_{1}\right)=\frac{M a_{1}}{Q_{1}}+M c_{1}+\frac{Q_{1} c_{1} r_{1}}{2}$

\subsubsection{Supplier's inventory cost}

In the supply chain network, the total demand for $M$, Set up cost per order of $a_{2}$, the cost per order for products unit price is $c_{2}$, the inventory ratio is $r_{2}$, each time order quantity is $Q_{2}$, the ordering cost is :

$C\left(Q_{2}\right)=\frac{M a_{2}}{Q_{2}}+M c_{2}+\frac{Q_{2} c_{2} r_{2}}{2}$

\subsubsection{The total cost of supply chain}

According to the description above, the total cost of supply chain:

$$
T C=C\left(Q_{1}\right)+C\left(Q_{2}\right)=M\left(\frac{a_{1}}{Q_{1}}+\frac{a_{2}}{Q_{2}}\right)+M\left(c_{1}+c_{2}\right)+\frac{1}{2}\left(Q_{1} c_{1} r_{1}+Q_{2} c_{2} r_{2}\right)
$$

Therefore, the inventory model can be described as:

$\operatorname{Min} T C=\operatorname{Min}\left\{C\left(Q_{1}\right)+C\left(Q_{2}\right)\right\}=\operatorname{Min}\left\{M\left(\frac{a_{1}}{Q_{1}}+\frac{a_{2}}{Q_{2}}\right)+M\left(c_{1}+c_{2}\right)+\frac{1}{2}\left(Q_{1} c_{1} r_{1}+Q_{2} c_{2} r_{2}\right)\right\}(6)$ 
In order to obtain the minimum inventory, combined with the model of economic order, supplier order $Q_{2}$ quantity of goods with the core manufacturing enterprise $Q_{1}$ there is a linear relationship between: $Q_{2}=n Q_{1}$, therefore, the inventory model can be simplified as:

$\operatorname{MinTC}=\operatorname{Min}\left\{C\left(Q_{1}\right)+C\left(Q_{2}\right)\right\}=\operatorname{Min}\left\{\frac{M}{Q_{1}}\left(a_{1}+\frac{a_{2}}{n}\right)+M\left(c_{1}+c_{2}\right)+\frac{Q_{1}}{2}\left(c_{1} r_{1}+n c_{2} r_{2}\right)\right\}(7)$

In type (7) $n$ and $Q_{1}$, respectively, partial derivatives, can be obtained:

$-\frac{M a_{2}}{n^{2} Q_{1}}+\frac{c_{2} r_{2} Q_{1}}{2}=0$

$-\frac{M}{Q_{1}^{2}}\left(a_{1}+\frac{a_{2}}{n}\right)+\frac{1}{2}\left(c_{1} r_{1}+n c_{2} r_{2}\right)=0$

By (8), (9) can solve:

$Q_{1}=\sqrt{\frac{2 M a_{1}}{c_{1} r_{1}}}$

$n=\sqrt{\frac{a_{2} c_{1} r_{1}}{a_{1} c_{2} r_{2}}}$

Quantity of goods and order lead time stability, Get the reorder point $R$ to: $R=D L$, where $D$ for time from order to receiving; $L$ for the average demand per unit time.

\subsection{Model solution and application}

A CEME is development earlier cement building material equipment enterprises in the north of our country. By expanding the scale and technological innovation constantly, the enterprises have occupied a favorable market share in the cement building material equipment industry currently and their products are exported to overseas markets. As the core manufacturing enterprise of cement equipment industry, its superior supplier is distributed throughout the country. Each cement production line contains hundreds of thousands of parts so that the purchasing cost of raw materials accounts for more than $70 \%$. Inventory management goal is to try to cut the order cost, reduce the pressure of inventory, which is required to determine the optimal order quantity of each parts and the reorder point level.

In this paper, a core material of the enterprise is selected to verify this model, and the material parameters are as follows: supplier cost per order $a_{1}=4800$, core enterprise cost per order $a_{2}=4800$, supply material price $c_{1}=615$, the core enterprise material unit price $c_{2}=950$, supplier stock ratio $r_{1}=0.11$, core enterprise stock ratio $r_{2}=0.15$, the amount of market demand forecasting $M=145013$,order lead time $D=1$.

To verify the validity of the model, we use computer language to simulate the operation of the model under the given conditions. The optimal order quantity and reorder point level of the material can be obtained by inputting the parameters into the interface shown in Figure 5. The optimal order quantity of the core manufacturing enterprise material is 4536, reorder point level is 3973. Other parts inventory control strategy can use the same method.

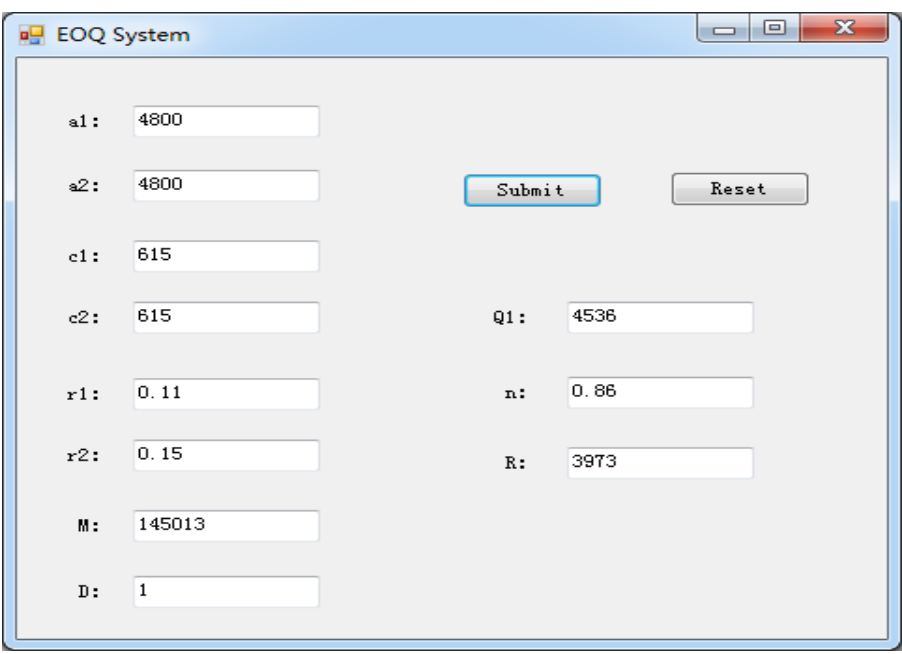

Fig 5 Optimal order quantity calculation

\section{CONCLUSION}

Setting inventory control strategy and strengthening the inventory data accuracy of enterprise is helpful to solve problems of inventory. The demand of the market is the motive force of enterprise development, especially in the supply chain inventory. Any deviation of beginning stage will cause great changes in the end. In this paper, based on the tier one supplier conditions, the core manufacturing inventory control model is established and the economic order quantity of the material is studied. The rational allocation of inventory and management are achieved by taking into account the purchasing cost, inventory maintenance costs and other factors.

\section{REFERENCES}

Enright M J, Scott E E, Chang K. Regional powerhouse: the greater Pearl River Delta and the rise of China [M]. Chichester: Wiley, 2005.

Klausner M, Hendrickson C T. Reverse-logistics strategy for product take-back[J]. Interfaces, 2000, 30(3): 156-165.

Stewart G. Supply-chain operations reference model (SCOR): the first cross-industry framework for integrated supplychain management[J]. Logistics information management, 1997, 10(2): 62-67.

Yi W. Logistics Rationalization: The Third Profit Source of Small and Medium Supermarkets[J]. Commercial Research, 2006, 3: 56-57. 